\title{
A Step Up for Extracorporeal Membrane Oxygenation: Active Rehabilitation
}

Extracorporeal membrane oxygenation (ECMO) has been used in an increasing number of centers as a bridge to lung transplant. ${ }^{1-4}$ It is recognized that as the lungs fail, invasive mechanical ventilation may not fulfill the optimal goals as a bridge to transplant. There have now been several international reports of ECMO as a successful bridge to transplant in patients who are awake and non-ventilated ("awake ECMO"). There is sound physiological rationale to minimize both mechanical ventilation and sedation in these cohorts, particularly when the waiting times for lung transplantation are increasing. In fact, invasive mechanical ventilation is potentially associated with ventilator-induced lung injury, ${ }^{5,6}$ ventilator-associated pneumonia, and ICU acquired weakness ${ }^{7,8}$ which may reduce the likelihood of transplant success and survival. ${ }^{9}$ Overall, outcomes following lung transplantation in patients bridged with extracorporeal life support, including ECMO, have been variable, depending on the patients, their indication for transplantation, and the configuration and duration of extracorporeal support. ${ }^{10-14}$

The main benefits of awake ECMO are that the patient can eat, drink, communicate, and participate in active rehabilitation, which may be an important predictor of outcome, as reported in this issue by Rehder et al. ${ }^{15}$ In theory, early use of awake ECMO may result in more physically and physiologically stable patients, as compared to those receiving invasive mechanical ventilation at the time of lung transplantation, which may translate into improved post-transplant outcomes. Indeed, some investigators have cautioned that the use of awake ECMO may lower the risk profile of recipients, resulting in a lower priority on the waiting list. ${ }^{12}$

In the largest case series to date, Fuehner and colleagues reported data from a retrospective single center analysis of 26 patients receiving awake ECMO, compared to a historical control group of 34 patients receiving conventional mechanical ventilation. ${ }^{2}$ Survival at 6 months after lung transplant was $80 \%$ in the awake ECMO group, compared to $50 \%$ in the mechanical ventilation group. Of note, the survival rate of the awake ECMO group decreased to $43 \%$ when secondary intubation became necessary, highlighting the importance of careful patient selection.

In this issue of the Journal, Rehder and colleagues take the management of awake ECMO one step further and include active rehabilitation. They report unique data from a case series of 9 consecutive patients bridged to lung transplant with ECMO at a single tertiary center, comparing 5 patients who received awake ECMO, active rehabilitation, and ambulation pre-transplant to 4 patients who received ECMO with sedation and mechanical ventilation and without active rehabilitation. ${ }^{15}$ While the study in itself was a small, retrospective case series, it helps to build a stronger case for awake and ambulatory ECMO as a safe and feasible option for pre-transplant rehabilitation as a bridge to transplant and recovery.

\section{See the Original Study on Page 1291}

Few centers that have utilized awake ECMO have reported specific rehabilitation exercises undertaken by their patients. The Table summarizes the available data on rehabilitation during awake ECMO.

Rehder et al report that all patients managed with awake ECMO pre-transplant mobilized within 5 days, and 3 patients within 48 hours of ECMO cannulation. Four of the patients in the active rehabilitation group ambulated on ECMO, and one patient participated in resistance exercises and sitting balance exercises over the edge of the bed prior to transplant. They had increased duration of mechanical ventilation and ECMO pre-transplant, possibly due to delayed listing for transplant during the rehabilitation process. All patients in the active rehabilitation group survived to 1-year follow-up, and they had reduced stay in both ICU and hospital. These 1-year outcomes for bridge to transplant are comparable to recent studies (range for survival $74-96 \%) .{ }^{10,12,17,18}$

Safety considerations for the use of awake ECMO include careful patient selection, early cannulation with ECMO, using a single cannulation site in the upper body (ie, internal jugular or subclavian vein) to allow for maximal mobility, and a multidisciplinary effort. Importantly, the ability to use a single, dual-lumen cannula in the upper body for extracorporeal life support may be limited by patient size and/or flow rate required to provide adequate gas exchange support. ${ }^{19}$ Persistent hypoxemia despite maximal flow with a single dual-lumen cannula may necessitate an additional venous drainage cannula (eg, femoral vein), limiting the safety and feasibility of awake 
A Step Up for Extracorporeal Membrane Oxygenation: Active Rehabilitation

Table. Rehabilitation During Awake ECMO

\begin{tabular}{|c|c|c|c|c|c|c|c|c|}
\hline First Author & Year & $\begin{array}{l}\text { Awake } \\
\text { ECMO } \\
\text { no. }\end{array}$ & $\begin{array}{l}\text { Age } \\
\text { y }\end{array}$ & $\begin{array}{c}\text { Primary Diagnosis } \\
\text { Cystic Fibrosis } \\
\text { no. }\end{array}$ & $\begin{array}{l}\text { ECMO } \\
\text { Duration } \\
\quad \mathrm{d}\end{array}$ & $\begin{array}{l}\text { Ambulation as } \\
\text { Rehabilitation } \\
\text { no. }\end{array}$ & $\begin{array}{c}\text { ICU Stay } \\
\mathrm{d}\end{array}$ & $\begin{array}{c}\text { Survived to } \\
\text { Transplant } \\
\%\end{array}$ \\
\hline Rehder $^{15}$ & 2013 & 5 & 28 & 4 & 8 & 4 & 27 & 100 \\
\hline Hoopes $^{12}$ & 2013 & 28 & 45 & 7 & 14 & 19 & 31 & 100 \\
\hline Fuehner $^{2}$ & 2012 & 26 & 44 & 5 & 9 & 0 & 18 & 77 \\
\hline Chierichetti ${ }^{1}$ & 2012 & 7 & 32 & ND & 12 & 0 & 29 & 100 \\
\hline Hayes ${ }^{16}$ & 2012 & 4 & 28 & 4 & 8 & 4 & ND & 100 \\
\hline Garcia $^{4}$ & 2011 & 10 & 45 & 0 & 20 & 4 & 28 & 67 \\
\hline \multicolumn{9}{|c|}{$\begin{array}{l}\text { Values are mean, except for survived to transplant. } \\
\text { ECMO = extracorporeal membrane oxygenation } \\
\text { ND }=\text { no data available }\end{array}$} \\
\hline
\end{tabular}

ECMO. Other studies have reported successful rehabilitation with treadmill walking, ${ }^{16}$ and transfers from bed to chair. $^{4}$

Early mobilization may be an important intervention to reduce the negative side effects of intubation, mechanical ventilation, and bed rest. ${ }^{20}$ It may be particularly important in the cohort of patients who are critically ill pretransplant and require ECMO as a bridge to transplant with an uncertain waiting period for donor lungs. There may also be potential for the use of extracorporeal life support in other patient populations to facilitate rehabilitation and prevent intubation, such as severe respiratory failure with ARDS or exacerbations of COPD. ${ }^{4}$ Indeed, recent case series have demonstrated the feasibility of using low-flow extracorporeal carbon dioxide removal to obviate the need for invasive mechanical ventilation in hypercapnic COPD patients failing noninvasive ventilation. ${ }^{21,22}$ However, many of the patients in these studies had femoral cannulation, limiting the ability to provide more intensive rehabilitation, which may have synergistic benefits when coupled with reduced analgosedation off invasive mechanical ventilation.

This is an area of critical care that is difficult to study using randomized controlled trials, due to small available numbers of patients and rapidly evolving medical practice; however, the need for validation of this study is clear. Further studies are required to confirm that rehabilitation during extracorporeal life support is safe and feasible. These studies will need to describe the most effective type of rehabilitation exercises to maximize pa-

The authors have disclosed no conflicts of interest.

Correspondence: Eddy Fan MD PhD, Interdepartmental Division of Critical Care Medicine, Toronto General Hospital, 585 University Avenue, 11C-1167, Toronto, Ontario, Canada M5G 2N2. E-mail: eddy.fan@uhn.ca.

DOI: $10.4187 /$ respcare.02606 tient-important outcomes, with particular emphasis on investigating the long-term effects of awake extracorporeal life support on physical function, health related quality of life, and return to work. ${ }^{23}$

Carol L Hodgson PhD Australian and New Zealand Intensive Care Society Research Centre Monash University Melbourne, Victoria, Australia

Eddy Fan MD PhD Interdepartmental Division of Critical Care Medicine Toronto General Hospital University of Toronto Toronto, Ontario, Canada

\section{REFERENCES}

1. Chierichetti M, Santini A, Pagan F, Critti S, Lissoni A, Gattinoni L. ECMO in nonintubated patients as a bridge to lung transplant: our experience. Crit Care 2012;16(Suppl 1):97.

2. Fuehner T, Kuehn C, Hadem J, Wiesner O, Gottlieb J, Tudorache I, et al. Extracorporeal membrane oxygenation in awake patients as bridge to lung transplantation. Am J Respir Crit Care Med 2012; 185(7):763-768.

3. Javidfar J, Brodie D, Iribarne A, Jurado J, Lavelle M, Brenner K, et al. Extracorporeal membrane oxygenation as a bridge to lung transplantation and recovery. J Thorac Cardiovasc Surg 2012;144(3): 716-721.

4. Garcia JP, Kon ZN, Evans C, Wu Z, Iacono AT, McCormick B, Griffith BP Ambulatory veno-venous extracorporeal membrane oxygenation: innovation and pitfalls. J Thorac Cardiovasc Surg 2011; 142(4):755-761.

5. Fan E, Villar J, Slutsky A. Novel approaches to minimize ventilatorinduced lung injury. BMC Med Mar 28 2013;11(1):85.

6. Gattinoni L, Carlesso E, Langer T. Towards ultraprotective mechanical ventilation. Curr Opin Anaesthesiol 2012;25(2):141-147.

7. Fan E, Zanni JM, Dennison CR, Lepre SJ, Needham DM. Critical illness neuromyopathy and muscle weakness in patients in the intensive care unit. AACN Adv Crit Care 2009;20(3):243-253.

8. Saxena MK, Hodgson CL. Intensive care unit acquired weakness. Anaesth Intensive Care Med 2012;13(4):145-147. 


\section{A Step Up for Extracorporeal Membrane Oxygenation: Active Rehabilitation}

9. Gonzalez-Castro A, Suberviola B, Llorca J, Gonzalez-Mansilla C, Ortiz-Melon F, Minambres E. Prognosis factors in lung transplant recipients readmitted to the intensive care unit. Transplant Proc 2007; 39(7):2420-2421.

10. Toyoda Y, Bhama JK, Shigemura N, Zaldonis D, Pilewski J, Crespo M, Bermudez C. Efficacy of extracorporeal membrane oxygenation as a bridge to lung transplantation. J Thorac Cardiovasc Surg 2013; 145(4):1065-1071.

11. Lang G, Taghavi S, Aigner C, Rényi-Vámos F, Jaksch P, Augustin $\mathrm{V}$, et al. Primary lung transplantation after bridge with extracorporeal membrane oxygenation: a plea for a shift in our paradigms for indications. Transplantation 2012;93(7):729-736.

12. Hoopes CW, Kukreja J, Golden J, Davenport DL, Diaz-Guzman E, Zwischenberger JB. Extracorporeal membrane oxygenation as a bridge to pulmonary transplantation. J Thorac Cardiovasc Surg 2013; 145(3):862-867; discussion 867-868.

13. Gottlieb J, Warnecke G, Hadem J, et al. Outcome of critically ill lung transplant candidates on invasive respiratory support. Intensive Care Med 2012;38(6):968-975.

14. Mason DP, Thuita L, Nowicki ER, Murthy SC, Pettersson GB, Blackstone EH. Should lung transplantation be performed for patients on mechanical respiratory support? The US experience. J Thorac Cardiovasc Surg 2010;139(3):765-773 e761.

15. Rehder KJ, Turner DA, Hartwig MG, Williford WL, Bonadonna D, Walczak RJ Jr, et al. Active rehabilitation during extracorporeal membrane oxygenation as a bridge to lung transplantation. Respir Care 2013;58(8):1291-1298.

16. Hayes D Jr, Kukreja J, Tobias JD, Ballard HO, Hoopes CW. Ambulatory venovenous extracorporeal respiratory support as a bridge for cystic fibrosis patients to emergent lung transplantation. J Cyst Fibros 2012;11(1):40-45

17. Hämmäinen P, Schersten H, Lemström K, Riise GC, Kukkonen S, Swärd K, et al. Usefulness of extracorporeal membrane oxygenation as a bridge to lung transplantation: a descriptive study. J Heart Lung Transplant 2011;30(1):103-107.

18. Bermudez CA, Rocha RV, Zaldonis D, Bhama JK, Crespo MM, Shigemura N, et al. Extracorporeal membrane oxygenation as a bridge to lung transplant: midterm outcomes. Ann Thorac Surg 2011; 92(4):1226-1232.

19. Chimot L, Marqué S, Gros A, Gacouin A, Lavoué S, Camus C, Le Tulzo Y et al. Avalon bicaval dual-lumen cannula for venovenous extracorporeal membrane oxygenation: survey of cannula use in France. ASAIO J 2013;59(2):157-161.

20. Schweickert WD, Pohlman MC, Pohlman AS, Nigos C, Pawlik AJ, Esbrook CL, et al. Early physical and occupational therapy in mechanically ventilated, critically ill patients: a randomised controlled trial. Lancet 2009;373(9678):1874-1882.

21. Burki NK, Mani RK, Herth FJ, Schmidt W, Teschler H, Bonin F, et al. A novel extracorporeal $\mathrm{CO}_{2}$ removal system: results of a pilot study of hypercapnic respiratory failure in patients with COPD. Chest 2013;143(3):678-686.

22. Kluge S, Braune SA, Engel M, Nierhaus A, Frings D, Ebelt H, et al. Avoiding invasive mechanical ventilation by extracorporeal carbon dioxide removal in patients failing noninvasive ventilation. Intensive Care Med 2012;38(10):1632-1639.

23. Hodgson CL, Hayes K, Everard T, Nichol A, Davies AR, Bailey MJ, et al. Long-term quality of life in patients with acute respiratory distress syndrome requiring extracorporeal membrane oxygenation for refractory hypoxaemia. Crit Care 2012;16(5):R202. 